\title{
Corrigendum: Perceptual factors contribute more than acoustical factors to sound localization abilities with virtual sources
}

\author{
Guillaume Andéol $^{1 *}$, Sophie Savel ${ }^{2}$ and Anne I. Guillaume ${ }^{3}$ \\ ${ }^{1}$ Département Action et Cognition en Situation Opérationnelle, Institut de Recherche Biomédicale des Armées, Brétigny sur \\ Orge, France, ${ }^{2}$ Laboratoire de Mécanique et d'Acoustique, Centre National de la Recherche Scientifique, UPR 7051, Equipe \\ Sons, Aix-Marseille Université, Centrale Marseille, Marseille, France, ${ }^{3}$ Laboratoire d'Accidentologie, de Biomécanique et \\ d'Étude du Comportement Humain, Nanterre, France
}

Keywords: sound localization, perceptual learning, procedural learning, head-related transfer function, individual differences

\section{OPEN ACCESS}

Edited and reviewed by: Brian Simpson,

Air Force Research Laboratory, USA

*Correspondence: Guillaume Andéol guillaume.andeo/@irba.fr

Specialty section: This article was submitted to Auditory Cognitive Neuroscience,

a section of the journal

Frontiers in Neuroscience

Received: 04 July 2016

Accepted: 22 July 2016

Published: 08 August 2016

Citation:

Andéol G, Savel S and Guillaume Al

(2016) Corrigendum: Perceptual factors contribute more than

acoustical factors to sound localization abilities with virtual sources. Front. Neurosci. 10:363.

doi: 10.3389/fnins.2016.00363

\section{A corrigendum on}

Perceptual factors contribute more than acoustical factors to sound localization abilities with virtual sources

by Andéol, G., Savel, S., and Guillaume, A. (2015). Front. Neurosci. 8:451. doi: 10.3389/fnins.2014.00451

Reason for Corrigendum:

Due to an oversight, there was a mistake in the Figure 2 as published. The black plots in the published Figure 2 were accidentally replaced with a duplicate of Figure 8 . The correct version of Figure 2 appears below, this figure corresponds with the written data in the main article text.

The authors apologize for the mistake.

This error does not change the scientific conclusions of the article in any way.

\section{AUTHOR CONTRIBUTIONS}

GA wrote the corrigendum. SS and AG viewed and approved this Corrigendum.

Conflict of Interest Statement: The authors declare that the research was conducted in the absence of any commercial or financial relationships that could be construed as a potential conflict of interest.

Copyright $\odot 2016$ Andéol, Savel and Guillaume. This is an open-access article distributed under the terms of the Creative Commons Attribution License (CC BY). The use, distribution or reproduction in other forums is permitted, provided the original author(s) or licensor are credited and that the original publication in this journal is cited, in accordance with accepted academic practice. No use, distribution or reproduction is permitted which does not comply with these terms. 


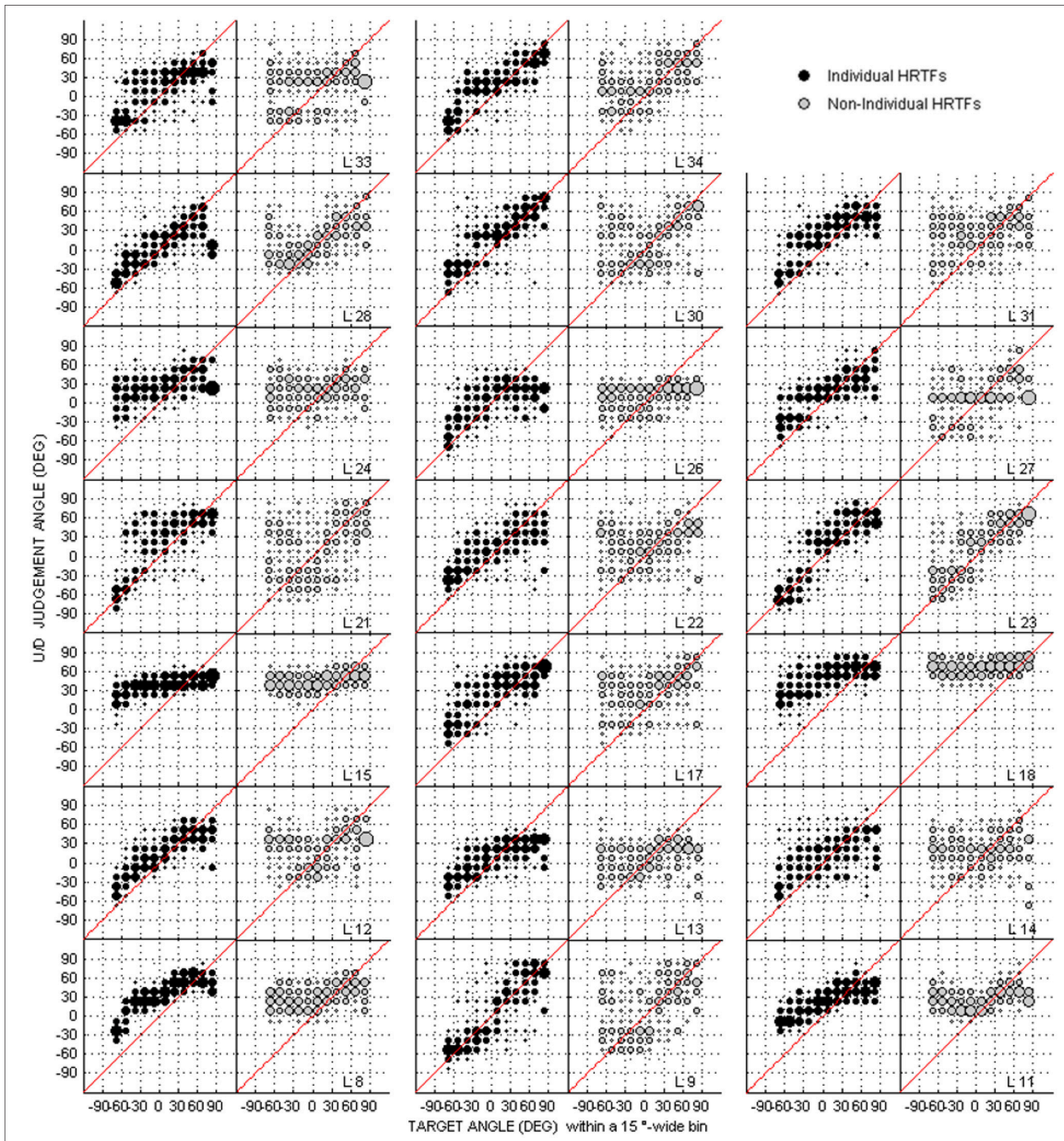

FIGURE 2 | Individual judgment position against target position with individual and non-individual HRTFs (black and gray dots, respectively) at the pre-test in the up/down dimension. Each panel couple is for a different listener $(N=20)$. 